\title{
A randomised controlled trial among cleaners- Effects on strength, balance and kinesiophobia
}

Marie Birk Jørgensen ${ }^{1,2^{*}}$, John Ektor-Andersen ${ }^{3}$, Gisela Sjøgaard ${ }^{4}$, Andreas Holtermann ${ }^{1}$ and Karen Søgaard ${ }^{4}$

\begin{abstract}
Background: Cleaners constitute a job group with poor health and low socioeconomic resources. Therefore, there is a great need for scientifically documented health promoting initiatives for cleaners. However, both workplace initiatives and high quality intervention studies are lacking. The aim of this study was to evaluate the effects of a 3month workplace trial with interventions to improve physical or cognitive behavioural resources among cleaners.

Methods: A cluster randomised controlled trial was conducted among 294 female cleaners from 9 workplaces. The participants were allocated to three groups: Physical coordination training $(P C T, n=95)$, Cognitive behavioural theory-based training (CBTr, $n=99)$ and Reference group (REF, $n=100)$. Interventions were conducted during work hours for an average of 1 hour/week. Muscle strength was measured by maximal voluntary contractions in trunk/extension, and shoulder abduction/elevation. Postural balance was measured on a force platform.

Kinesiophobia was measured with Tampa Scale for Kinesiophobia. Test and questionnaires were completed at baseline and at 3-month follow-up and analyses followed the intention-to-treat (ITT) principle with last observation carried forward in case of missing data at follow-up. Reports and analyses are given on true observations as well.

Results: ITT-analyses revealed that PCT improved strength of the trunk $(p<.05)$ and postural balance $(p<.05)$ compared to CBTr and REF. Based on true observations the strength and balance improvements corresponded to $\sim 20 \%$ and $\sim 16 \%$, respectively. ITT-analyses showed that CBTr reduced kinesiophobia compared to PCT and REF ( $p$ $<.05)$. Based on true observations, the improvement corresponded to a 16\% improvement.

Conclusion: This workplace-based intervention study including PCT and CBTr among cleaners improved strength and postural balance from PCT, and kinesiophobia from CBTr. The improved strength, postural balance and kinesiophobia may improve the cleaners' tolerance for high physical work demands. Future studies should investigate the potential in the combination of PCT and CBTr in a workplace intervention.
\end{abstract}

Trial registration: Current controlled trials ISRCTN96241850

\section{Background}

Cleaners defined as people whose main job task is cleaning work (janitors, custodians, cleaning assistants) constitute a job group with poor health and low socioeconomic resources [1-4]. Therefore, there is a great need for scientifically documented health promoting initiatives for cleaners. However, high quality intervention studies are lacking [5].

Ergonomic interventions have been conducted to prevent deterioration of cleaners' health by reducing the physical workload $[1,6,7]$. However, due to a high degree

\footnotetext{
* Correspondence: mbj@nrcwe.dk

'The National Research Centre for the Working Environment, Lersø Parkallé 105, 2100 Copenhagen, Denmark

Full list of author information is available at the end of the article
}

of work intensification, and the fact that some cleaning tasks are currently no further changeable, cleaning will remain a physically heavy work [4]. Another preventive strategy may be to improve the tolerance to the physical workload of the cleaner by enhancing the physical resources or the ability to cope with musculoskeletal pain [5]. High physical resources have previously been shown important for tolerating high physical work demands [8]. Moreover, pain-related fear of movement (kinesiophobia) has been shown to be a stronger predictor for future disability than pain itself [9].

Intervention programmes with physical training to improve strength have been successfully tested among office workers $[10,11]$. However, no previous high quality studies have investigated the effects of physical

\section{() Biomed Central}


training on physical resources among cleaners. Cleaning work frequently involves pushing and pulling, standing, walking and squatting and job tasks with bent back, elevated hands and twisted body [2]. Therefore, interventions to improve muscle strength and postural control such as coordination training may be particularly relevant for preventing deterioration in this job group.

Several intervention studies have successfully focused on improving patients' pain coping abilities through programmes with cognitive behavioural therapy (CBT) as secondary prevention [12]. However, CBT has seldom been applied for primary prevention of health impairments or deterioration among working populations [13]. Because cleaners have high physical work demands and high prevalence of pain [1], pain-related fear of movement may be of particular importance for the risk of functional deterioration in this job group. Therefore, interventions to reduce pain-related fear of movement may be especially relevant for this job group.

The main aim was to test if workplace intervention trials with physically intensive strength coordination training (PCT) can improve muscle strength and postural control and if cognitive behavioural theory-based training (CBTr) can reduce kinesiophobia. Therefore, a randomised controlled trial with a PCT programme and a CBTr programme specifically tailored for cleaners was conducted on 9 cleaning workplaces in Denmark.

\section{Methods}

The study is a part of the previously described FINALE (Frame for INterventions for preserved work Ability; Long term Effect) programme [5] aiming at investigating preventive initiatives against deterioration among work groups with high physical work demands. The study was a cluster randomised controlled intervention conducted at 9 cleaning workplaces in Denmark. Approval was received from the local ethics committee (H-C-20070033). The primary outcomes for this clinical trial are work ability and sickness absence. The current paper evaluates the mediating variables at 3-months follow-up. Trial effects on the primary outcomes are reported in Jorgensen et al. (submitted). Other publications in relation to the trial can be found by visiting http://www. controlled-trials.com and search for our unique trial registration number: ISRCTN96241850.

\section{Recruitment procedure}

Participants were recruited from cleaning work places in the urban, rural and metropolitan regions of Denmark. Recruited participants were required to be employed at least 20 hours/week at the workplace, and primarily work during day hours. Their main work task had to be cleaning, but their job could also involve other service tasks such as washing, kitchen work or attending patients. All eligible employees $(\mathrm{N}=758)$ were invited to an information meeting during their working hours, asked to answer a screening questionnaire, and to give consent if willing to enrol in the study. For employees who did not attend the information meeting, managers subsequently handed them written information on the project and screening questionnaires with a stamped addressed envelope. Among the eligible employees, 394 consented to participate, and these were invited to answer a questionnaire. Among the consenters, 363 (48\%) entered the intervention study. A large fraction of immigrants are employed at cleaning workplaces in Denmark, but Danish language skills are required. Therefore, all written and oral communication was conducted in Danish. Language and reading difficulties were dealt with through guidance from the research personnel or collegial assistance. Further details of the recruitment procedure has previously been reported [14].

\section{Randomisation procedure}

For the cluster randomisation procedure, each workplace was considered a stratum. Clusters depended on work teams where possible or were made up from groups either in which employees had lunch, groups where they worked in close proximity to each other, or groups who reported to the same manager. Clusters were matched on sex, age and job seniority. The randomisation was made by lot conducted by blinded staff. To obtain a homogeneous group and due to the high proportion of females in the job group, the 69 males were excluded from further analyses in the present study $(\mathrm{PCT}=25$ males, $\mathrm{CBTr}=22$ males, $\mathrm{REF}=22$ males).

\section{Design}

The female cleaners were randomised into PCT ( $\mathrm{n}=$ $95)$, CBTr $(n=99)$ or REF $(n=100)$. Both data collection and interventions were conducted during the cleaners' working hours. Questionnaires were collected and physical tests conducted at baseline and after three months intervention.

\section{Interventions}

The PCT was instructor-guided and offered 3 times a week during 12 weeks in sessions of 20 minutes duration at the workplace during working hours. Six intensive physical coordination exercises with 2-4 levels of progression were performed. The exercises were four point kneeling, prone plank, bridge, vertical plank, bodyblade and horizontal side support and are described in detail elsewhere [15]. Each training session began with a short warm up consisting of ballistic stretching. During the first 1 or 2 weeks, only 3-4 exercises were presented 
at each session until the performance was technically correct. Thereafter each exercise was performed 2 times 25 seconds in a circuit programme. The exercises all involved a high demand of coordination and were performed at the maximal level of progression, challenging the performer optimally during the 25 seconds with a work load corresponding to $60-80 \%$ of their maximal voluntary muscle strength. One or two instructors supervised the participants' performances and offered corrections when necessary.

The CBTr was instructor-guided and offered every second week during 12 weeks in two-hour sessions at the workplace during working hours. The programme was a modified version of the programme developed by Linton $[16,17]$. With respect to the hypothesis of this paper, the purpose of the programme was to reduce kinesiophobia and thereby diminish negative effects of kinesiophobia. Therefore, the programme focused on improving the participants' understanding of pain, the experience of pain, and the anticipation of pain by performing cognitive exercises on how physical activity not necessarily leads to pain. Cognitive and behavioural exercises were performed to train the ability to function despite pain (i.e. pain coping, increasing health behaviour, adapt skills to daily life). Moreover, the positive long-term effects from appropriate pain coping were discussed [17]. Every session was planned with the same general outline: feedback on homework from previous session, introduction to today's theme of the session, a short lecture on the theme, problem-solving exercises and training of new skills (i.e. applied relaxation training) [18]. To enable the participants to train the applied relaxation programme during the workday, they received an $\mathrm{mp} 3$ with the necessary instructions.

\section{Measurements and analyses \\ Physical capacity}

Isometric muscle strength was tested in maximal voluntary contractions (MVC) with validated measures on trunk extension and flexion, and shoulder elevation [19]. For shoulder elevation and abduction strength, the participant was sitting upright in a height-adjustable chair with Bofors dynamometers $1 \mathrm{~cm}$ medial to the lateral edge of the acromion of each shoulder and $1 \mathrm{~cm}$ proximal from the olecranon of the elbow joints, respectively. For the trunk extension and flexion, the participant was standing in an upright position with a strap attached to a strain gauge dynamometer around the shoulders at the level of deltoid insertion. For MVC of the back extensor muscles, the subject faced the dynamometer with the pelvis against a plate placed with the upper edge aligned with the iliac crest of the subject. Correspondingly, for MVC of the abdominal muscles, the subject was placed with the back towards the dynamometer and the pelvis against the plate. The vertical distance between the L4/L5 level and the middle of the strap was measured for torque calculation. In these isometric positions, the cleaner was instructed to gradually build up force over $5 \mathrm{sec}$, then to keep maximal force for about 2 sec, and finally to lower the force slowly to zero. This MVC was performed at least three times for each exercise. If the third recording was more than $5 \%$ higher than the previous two recordings, a fourth test was performed, with a maximum number of five tests. Strong standardized verbal encouragement was given during all trials. Cleaners were excluded from this test in case of self-reported or measured high blood pressure, angina pectoris, previous herniated disc or use of heart or lung medicine. Furthermore, the cleaners were asked about musculoskeletal symptoms within the last 7 days. In case of a positive answer, they were asked if they felt considerable pain in this specific body region on the test day. If so, they were excluded from the muscle strength measurement affecting this body region. A high proportion of the cleaners was in pain or had elevated blood pressure, as previously reported [20]. All cleaners were still invited to the randomised study.

A $30 \mathrm{sec}$ balance test was performed in an undisturbed environment. The participants were encouraged to take a break in between repetitions of the test whenever they felt their attention to the task decreased. A crew of trained experimenters conducted and gave standardized instructions to each test. Participants stood barefooted on a force platform (AMTI, platform type OR6-7-1000, amplifier type MSA-6) and were instructed to "stand as still as possible". During the balance test, indications of test progression (10 sec, $20 \mathrm{sec}$, test ends) were verbally informed to the participant from the experimenter. If the participant lost balance during tests and moved arms or feet from the starting position, a new trial was recorded. Two tests were performed in the Romberg position (standing with feet together, heelto-heel and toe-to-toe) with open and closed eyes [21]. The participants stood with their arms folded across their chest and their feet parallel to the $y$-axis of the platform. In the test with open eyes, participants were instructed to look at the black spot. The test was performed for $30 \mathrm{~s}$ and three trials were recorded for the test with closed eyes.

The force $(F x, F y$ and $F z)$ and moment $(M x, M y$ and $M z$ ) signals were sampled at $125 \mathrm{~Hz}$, and filtered $(10 \mathrm{~Hz}$ $4^{\text {th }}$ order Butterworth zero-phase low-pass filter). The COP consisting of the AP and medio-lateral (ML) components $\left(\left[x_{A P}, x_{M L}\right]=[M x / F z, M y / F z]\right)$ was calculated and decomposed into a rambling and trembling component. Subsequently, the $95 \%$ confidence ellipse areas (CEA) were calculated for the COP [22]. Participants were excluded from this specific test if reporting 
considerable pain, trauma (strain or overload) or physical restriction due to recent trauma in the neck, low back, hip, knee or ankle.

\section{Kinesiophobia}

Kinesiophobia is defined as "an irrational and debilitating fear of physical movement and activity resulting from a feeling of vulnerability to painful injure or (re) injury" [23]. Kinesiophobia is a marked or persistent fear that is often excessive or unreasonable, which is cued by the presence or anticipation of a pain-eliciting situation. Kinesiophobia is evident both among chronic pain patients [24] and in the general population with non-persistent pain [25]. Kinesiophobia is shown to precede avoidance-behaviour, which may have both physical and psychological health consequences [23]. Kinesiophobia was assessed by the questionnaire Tampa Scale for Kinesiophobia (TSK) [23]. A high value on the TSK indicates a high degree of kinesiophobia.

The TSK contains 17 items that are scored by 4point Likert scales with scoring options ranging from 1 $=$ "strongly disagree" to 4 = "strongly agree". The first 13 of the 17 items indicate increasing kinesiophobia with increasing scores and were phrased: "I'm afraid that I might injury myself if I exercise", "If I were to try to overcome it, my pain would increase", "My body is telling me I have something dangerously wrong", "People aren't taking my medical condition seriously enough", "My accident has put my body at risk for the rest of my life", "Pain always means I have injured my body", "I am afraid that I might injure myself accidentally", "Simply being careful that I do not make any unnecessary movements is the safest thing I can do to prevent my pain from worsening", "I wouldn't have this much pain if there weren't something potentially dangerous going on in my body", "Pain lets me know when to stop exercising so that I don't injure myself", "It's really not safe for a person with a condition like mine to be physically active", "I can't do all the things normal people do because it's too easy for me to get injured", "No one should have to exercise when he/she is in pain". Following these, four items with inverse structure were posed separately. The phrasing of these were: "My pain would probably be relieved if I were to exercise", "Just because something aggravates my pain does not mean it is dangerous ", "Although my condition is painful, I would be better off if I were physically active", "Even though something is causing me a lot of pain, I don't think it's actually dangerous". The scorings from the last four items were inverted before calculating the sum-score, thus ranging from 17-68. Some of the cleaners failed to answer the questionnaire, explaining the missing observation displayed from the number of responders in table 1.

\section{Statistics}

To determine if differences between the three groups had happened by chance in the randomisation, descriptive data regarding the variables age, height, weight, body mass index, fat \%, job seniority, distribution of immigrant and native cleaners, muscle strength, balance and kinseiophobia were reported. Since no differences appeared from these reports, the analyses on intervention effects were unadjusted. The effects of intervention on muscle strength, balance and kinesiophobia were evaluated in an intention-to-treat analysis using one-way analysis of variance (ANOVA) on the difference between baseline and follow-up, followed by Bonferroni corrected post-hoc-tests when relevant. Due to missing observations, observations were carried backward and forward at baseline and follow-up, respectively, thereby avoiding bias of non-random drop-out $[26,27]$. In addition, to display the true observations and to avoid false negative results, data were analysed exhaustive by performing the same analysis procedure only with true observations on both outcome measures at baseline and follow-up. This procedure was termed true-observations analysis. Finally, to obtain further power to the dataset, if no difference between REF and the other intervention group existed, both analyses were further explored in an aggregated analysis, collapsing REF with the inefficient intervention. For example, the PCT intervention effect on muscle strength and balance was tested against CBTr and REF combined, and the CBTr intervention effect on kinesiophobia was tested against PCT and REF combined. IBM SPSS statistics version 19 was used for all statistical analyses.

\section{Results}

\section{Employee flow}

There were 33, 40 and 26 cleaners who dropped out of the study from PCT, CBTr and REF, respectively, as given in Figure 1. Those who dropped out did not attend the follow-up measurements. Seventeen and eighteen percent did not receive the intervention at any time in the PCT and CBTr, respectively. Mean adherence rates (including those with zero adherence) were $37 \%$ and $49 \%$ in PCT and CBTr, respectively.

\section{Baseline characteristics}

Baseline characteristics of the participants in the three intervention groups are given in table 1. No differences between the three groups were found at baseline. Both mean for the participants at baseline, the intention-totreat baseline populations (with missing variables carried backwards) and the true observations baseline population (those with outcome measures both at baseline and follow-up) are displayed. A large fraction of the study 
Table 1 Baseline characteristics stratified on intervention groups

\begin{tabular}{|c|c|c|c|c|c|c|c|c|c|}
\hline \multirow[b]{2}{*}{ Baseline } & \multicolumn{3}{|c|}{$\begin{array}{l}\text { Physical coordination training } \\
\qquad(\mathrm{N}=95)\end{array}$} & \multicolumn{3}{|c|}{$\begin{array}{l}\text { Cognitive behavioural training } \\
\qquad(\mathrm{N}=99)\end{array}$} & \multicolumn{3}{|c|}{$\begin{array}{l}\text { Reference group } \\
(\mathrm{N}=100)\end{array}$} \\
\hline & $\mathrm{n}$ & Mean & SD & $\mathrm{n}$ & mean & SD & $\mathrm{n}$ & mean & SD \\
\hline Age (years) & 95 & 44 & 9.1 & 99 & 46 & 8.9 & 100 & 45 & 9.6 \\
\hline Height $(\mathrm{cm})+$ & 89 & 160 & 7.1 & 95 & 161 & 7.7 & 89 & 163 & 7.8 \\
\hline Weight (kg) & 87 & 73 & 14.5 & 95 & 72 & 17.1 & 87 & 73 & 14.5 \\
\hline $\mathrm{BMI}(\mathrm{kg} / \mathrm{m}$ & 87 & 28 & 5.1 & 95 & 28 & 5.9 & 87 & 28 & 5.0 \\
\hline Fat $\%$ & 85 & 36 & 7.5 & 95 & 35 & 8.2 & 82 & 35 & 8.3 \\
\hline Job seniority (years) & 74 & 9.4 & 9.1 & 83 & 9.9 & 8.1 & 78 & 10.3 & 9.6 \\
\hline Immigrants (\%) & 89 & 50.6 & - & 95 & 46.3 & - & 97 & 45.9 & - \\
\hline \multicolumn{10}{|l|}{ Muscle strength } \\
\hline Shoulder elevation (Nm) & 44 & 53.0 & 19.8 & 45 & 52.2 & 19.6 & 45 & 56.7 & 20.0 \\
\hline Shoulder abduction (Nm) & 43 & 31.7 & 11.4 & 46 & 31.5 & 11.9 & 41 & 30.1 & 6.7 \\
\hline Trunk flexion (Nm) & 48 & 93.2 & 29.5 & 47 & 103.7 & 44.9 & 51 & 101.5 & 29.9 \\
\hline Trunk extension (Nm) & 45 & 81.4 & 28.9 & 43 & 89.2 & 30.5 & 48 & 88.7 & 37.1 \\
\hline \multicolumn{10}{|l|}{ Balance } \\
\hline 95\% confidence ellipse (mm2) & 82 & 822.5 & 506.5 & 88 & 771.1 & 529.4 & 81 & 787.1 & 500.9 \\
\hline Rambling (mm2) & 82 & 495.7 & 324.7 & 88 & 442.9 & 295.6 & 81 & 453.8 & 274.7 \\
\hline Trembling (mm2) & 82 & 155.4 & 108.8 & 88 & 169.9 & 160.4 & 81 & 169.1 & 139.0 \\
\hline Kinesiophobia (Index TSK17) & 77 & 34.3 & 8.5 & 85 & 32.0 & 8.6 & 80 & 34.4 & 9.9 \\
\hline \multicolumn{10}{|l|}{ Intention-to-treat baseline } \\
\hline \multicolumn{10}{|l|}{ Muscle strength } \\
\hline Shoulder elevation (Nm) & 47 & 51.8 & 19.8 & 45 & 52.2 & 19.6 & 47 & 57.1 & 19.7 \\
\hline Shoulder abduction (Nm) & 47 & 33.6 & 13.1 & 47 & 31.8 & 12.0 & 44 & 30.4 & 6.9 \\
\hline Trunk flexion (Nm) & 51 & 93.7 & 29.0 & 47 & 103.7 & 44.9 & 52 & 101.1 & 29.7 \\
\hline Trunk extension (Nm) & 48 & 82.0 & 28.2 & 44 & 90.3 & 31.0 & 49 & 88.0 & 37.0 \\
\hline \multicolumn{10}{|l|}{ Balance } \\
\hline 95\% confidence ellipse (mm2) & 87 & 835.4 & 501.0 & 91 & 756.9 & 526.6 & 85 & 804.9 & 514.1 \\
\hline Rambling (mm2) & 87 & 506.6 & 327.5 & 91 & 435.4 & 293.8 & 85 & 463.9 & 278.5 \\
\hline Trembling (mm2) & 87 & 156.3 & 107.6 & 91 & 166.2 & 159.1 & 85 & 174.7 & 153.5 \\
\hline Kinesiophobia (Index TSK17) & 82 & 34.9 & 8.6 & 91 & 32.6 & 9.0 & 83 & 34.6 & 9.7 \\
\hline \multicolumn{10}{|l|}{ True observations baseline } \\
\hline \multicolumn{10}{|l|}{ Muscle strength } \\
\hline Shoulder elevation (Nm) & 26 & 52.0 & 19.9 & 23 & 51.4 & 19.3 & 24 & 55.9 & 21.2 \\
\hline Shoulder abduction (Nm) & 23 & 31.8 & 9.2 & 24 & 29.7 & 9.0 & 22 & 29.2 & 6.5 \\
\hline Trunk flexion (Nm) & 31 & 89.8 & 26.4 & 25 & 105.0 & 48.4 & 26 & 99.2 & 26.2 \\
\hline Trunk extension $(\mathrm{Nm})^{*}$ & 28 & 76.7 & 26.1 & 23 & 87.3 & 30.8 & 25 & 99.9 & 37.0 \\
\hline \multicolumn{10}{|l|}{ Balance } \\
\hline 95\% confidence ellipse (mm2) & 50 & 856.6 & 540.9 & 45 & 733.0 & 409.7 & 54 & 824.2 & 579.2 \\
\hline Rambling (mm2) & 50 & 517.4 & 333.6 & 45 & 430.2 & 268.9 & 54 & 470.6 & 314.7 \\
\hline Trembling (mm2) & 50 & 160.5 & 117.1 & 45 & 155.7 & 106.8 & 54 & 180.4 & 159.5 \\
\hline Kinesiophobia (Index TSK17) & 38 & 31.4 & 8.2 & 42 & 30.5 & 8.6 & 53 & 32.9 & 9.6 \\
\hline
\end{tabular}

The Baseline reflects all of the female cleaners with observations at baseline, Intention to treat baseline reflects all of the female cleaners with observations at baseline including those with missing observations, for whom values were carried backwards from follow up, and True observations baseline reflect those cleaners with observations at both baseline and follow-up. $\mathrm{N}=$ number of participants, $\mathrm{n}=$ number of observations, Nm = Newton meter, $\mathrm{SD}=\mathrm{Standard}$ deviation

population was immigrants, as given in Table 1. Among the immigrants, 49 different ethnic identities were present with the 8 most prevalent being Turkey, Marcedonia, Pakistan, Thailand, Philippines, Morocco, India and Serbia, representing $70 \%$ of the immigrants in the study population. Previously, studies on the immigrant population in the current study has been published $[20,28,29]$.

\section{Physical capacity}

Intervention effects are shown in table 2 on both intension-to-treat basis and on true observations. PCT significantly improved trunk flexion muscle strength in comparison with CBTr and REF separately $(\mathrm{p}=.01$ and .045) in intention-to-treat and in the aggregated analysis $(\mathrm{p}=.01)$. True observations revealed a $\sim 20 \%$ 


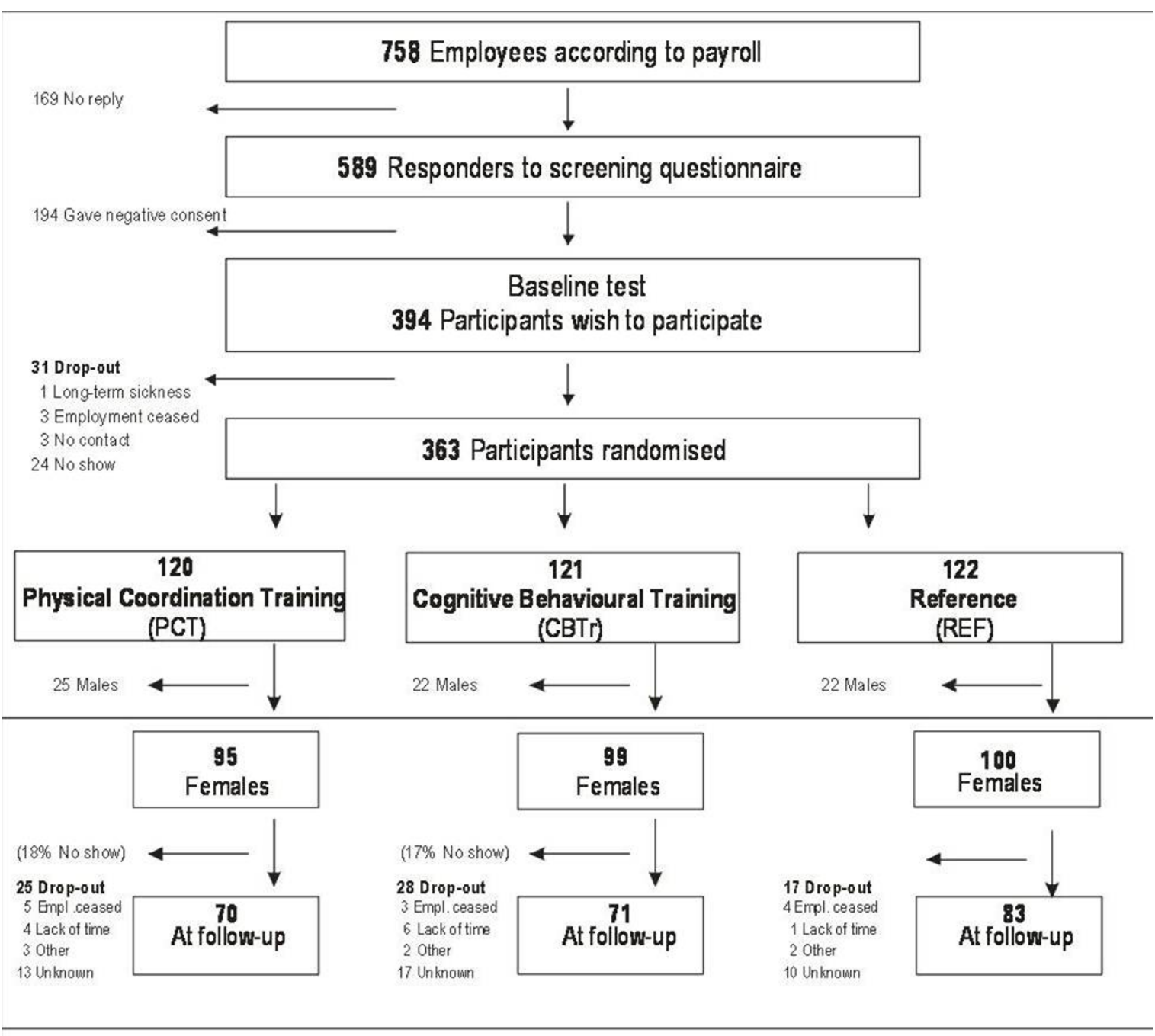

Figure 1 Flow of participants through the intervention study.

improved trunk muscle strength in PCT. Changes in none of the other muscle strength measures were significantly different after the intervention. PCT improved balance in rambling in comparison with $\operatorname{CBTr}(\mathrm{p}=.02)$ and there was a tendency to an improvement in comparison with REF alone $(\mathrm{p}=.07)$ in intention-to-treat. The PCT improvement was highly significant in the aggregated analysis $(\mathrm{p}=.004)$. True observations revealed a $\sim 16 \%$ improvement in rambling in $\mathrm{PCT}$. The improvement in $95 \%$ confidence ellipse showed a tendency to be better in the PCT compared to CBTr and REF ( $p=.087)$, and the difference was close to statistical significance in the aggregated analysis $(\mathrm{p}=.051)$. No change was found in trembling after the intervention. The analyses on the true observations provided similar results (table 2).

\section{Kinesiophobia}

The TSK had a high internal consistency, with Chronbach's alpha of 0.80 . The CBTr significantly reduced their kinesiophobia after the intervention in comparison with PCT ( $\mathrm{p}=$ .012 ), but not with respect to REF ( $\mathrm{p}=.457)$. However the difference was significantly different in the aggregated analysis, CBTr versus PCT and REF $(\mathrm{p}=.013)$. Furthermore, these differences were highly significant in the true observations analysis both against PCT $(\mathrm{p}=.008)$ and against PCT and REF aggregated $(\mathrm{p}=.01)$. The true observations revealed a $\sim 16 \%$ reduced kinesiophobia in CBTr.

\section{Discussion}

Main findings

This 3-month randomised controlled trial among female cleaners from 9 workplaces in Denmark significantly 
Table 2 Changes after the intervention on outcome variables stratified on intervention

\begin{tabular}{|c|c|c|c|c|c|c|c|c|c|c|}
\hline & \multicolumn{3}{|c|}{$\begin{array}{c}\text { Physical coordination } \\
\text { training }(\mathrm{N}=95)\end{array}$} & \multicolumn{3}{|c|}{$\begin{array}{c}\text { Cognitive behavioural } \\
\text { training }(\mathrm{N}=99)\end{array}$} & \multicolumn{3}{|c|}{$\begin{array}{l}\text { Reference group } \\
\quad(N=100)\end{array}$} & \multirow{2}{*}{$\begin{array}{c}\text { Aggregated analyses } \\
\text { p }\end{array}$} \\
\hline & $\mathrm{n}$ & mean & SD & $\mathrm{n}$ & mean & SD & $\mathrm{n}$ & mean & SD & \\
\hline \multicolumn{11}{|l|}{ Intention-to-treat } \\
\hline \multicolumn{11}{|l|}{ Muscle strength } \\
\hline Shoulder elevation ( $\mathrm{Nm}$ ) & 47 & 0.4 & 13.0 & 45 & 0.0 & 7.7 & 47 & 0.3 & 7.4 & \\
\hline Shoulder abduction (Nm) & 47 & 2.4 & 6.0 & 47 & 0.9 & 4.6 & 44 & 2.1 & 7.4 & \\
\hline Trunk flexion (Nm) & 51 & 11.7 & 24.1 & 47 & -2.6 & 19.4 & 52 & 2.1 & 15.0 & $* *$ \\
\hline Trunk extension (Nm) & 48 & 4.2 & 16.3 & 44 & -2.2 & 17.6 & 49 & 2.5 & 18.6 & \\
\hline \multicolumn{11}{|l|}{ Balance } \\
\hline 95\% confidence ellipse (mm2) & 87 & -69.7 & 295.4 & 91 & 28.2 & 265.9 & 85 & -16.5 & 320.4 & * \\
\hline Rambling (mm2) & 87 & -48.4 & 189.6 & 91 & 28.9 & 171.9 & 85 & 17.1 & 203.1 & $* *$ \\
\hline Trembling (mm2) & 87 & -3.7 & 68.6 & 91 & -3.8 & 55.6 & 85 & -16.2 & 99.3 & \\
\hline Kinesiophobia (Index TSK17) & 82 & 1.3 & 5.4 & 91 & -1.1 & 4.7 & 83 & 0.1 & 5.8 & * \\
\hline \multicolumn{11}{|l|}{ True observations } \\
\hline \multicolumn{11}{|l|}{ Muscle strength } \\
\hline Shoulder elevation (Nm) & 26 & 0.7 & 17.7 & 23 & 0.0 & 10.9 & 24 & 0.6 & 10.4 & \\
\hline Shoulder abduction (Nm) & 23 & 4.8 & 7.8 & 24 & 1.8 & 6.4 & 22 & 4.2 & 10.2 & \\
\hline Trunk flexion (Nm) & 31 & 19.3 & 28.6 & 25 & -4.9 & 26.6 & 26 & 4.3 & 21.2 & $* *$ \\
\hline Trunk extension (Nm)* & 28 & 7.2 & 21.0 & 23 & -4.2 & 24.5 & 25 & 4.9 & 26.1 & \\
\hline \multicolumn{11}{|l|}{ Balance } \\
\hline 95\% confidence ellipse (mm2) & 50 & -121.3 & 383.1 & 45 & 57.0 & 378.1 & 54 & -25.9 & 403.1 & $t$ \\
\hline Rambling (mm2) & 50 & -84.2 & 245.0 & 45 & 58.3 & 242.3 & 54 & 26.9 & 255.1 & $* *$ \\
\hline Trembling (mm2) & 50 & -6.5 & 90.7 & 45 & -7.7 & 79.4 & 54 & -25.4 & 124.1 & \\
\hline Kinesiophobia (Index TSK17) & 38 & 2.8 & 8.6 & 42 & -2.6 & 6.7 & 53 & 0.1 & 7.92 & $* *$ \\
\hline
\end{tabular}

Intention to treat reflects all the female cleaners enrolled to the study, who had an observation at baseline or at follow-up. In case of missing observations, values are carried backwards or forward from the available observation, leaving a delta-value of 0 . True observations reflect those with observations at both baseline and follow-up. $\mathrm{N}=$ number of participants, $\mathrm{n}=$ number of observations, $\mathrm{Nm}=$ Newton meter, $\mathrm{SD}=\mathrm{Standard}$ deviation, $\mathrm{p}=$ Level of significance, $+\mathrm{p}<0.1,{ }^{*} \mathrm{p}<$ $0.05,{ }^{* *} \mathrm{p}=/<0.01$. In aggregated analyses the non efficient intervention group is considered a reference and is merged with the reference group. E.g. for kinesiophobia cognitive behavioural training is tested against physical coordination training+reference and for all other outcomes physical coordination training is tested against cognitive behavioural training+reference. In the muscle strength test $\mathrm{n}$ is different due to the health-related exclusion (self-reported or measured high blood pressure, angina pectoris, previous herniated disc, use of heart or lung medicine or current considerable pain on the body regions specific to the test). $\mathrm{n}$ is limited in the balance test due to the health-related exclusion (considerable pain, trauma or physical restriction due to recent trauma in the neck, low back, hip, knee or ankle).

improved their individual physical and cognitive behavioural resources. The PCT intervention improved trunk muscle strength and balance, and the CBTr intervention reduced kinesiophobia. In the following, implications and perspectives on the improvements of these resources for the prevention of deterioration among cleaners will be discussed.

\section{Comparison with other studies}

Our study is the first RCT among workers with high physical work demands demonstrating a workplace training intervention to improve muscle strength in an ITT-analysis. It is well recognized that the dose of a work task is relative to the capacity of the performing worker $[30,31]$. Therefore, the relative physical work exposure on the musculoskeletal system of the worker can be considered reduced when strength improvements are obtained. Generally, the strength level of the cleaners in the current study was comparable to reports from previous studies with a representative sample of the Danish population [32] and a sample of Danish cleaners [8], although trunk strength was below the previous reports. High muscle strength has been shown to characterize senior ( $>8$ years) cleaners without muscle pain in comparison with cleaners with similar seniority with muscle pain [8]. Therefore, the increased muscle strength from the PCT may improve the cleaners' tolerance for high work loads and possibly reduce the risk for deterioration, i.e. musculoskeletal disorders.

The PCT was tailored to improve both strength and coordination of the cleaners. Accordingly, the PCT resulted in an improved postural balance. The PCT included training of the bracing manoeuvre, which produces a global co-activation of the muscles of the abdominal wall [33]. In our study, the only instruction that was given during the balance test was "stand as still as possible" and the test leader was blinded to the randomisation. Therefore, the improved balance may imply that the cleaners in PCT were able to transfer and use the improved strength and coordination of abdominal 
wall muscles in tasks not related to the training. Some studies suggest that poor stabilisation may predispose injury and musculoskeletal disorders [34-36]. Thus, the improvements in strength and balance in PCT may prevent deterioration of health among female cleaners in the longer term.

CBTr was shown to decrease kinesiophobia compared to both REF and PCT. Pain-related fear of movement is closely related to measures of disability and catastrophising [9,37-39]. Furthermore, kinesiophobia is shown to predict long-term recovery from pain-related functional disability among males with chronic non-specific low back pain [40] and improved kinesiophobia among work-disabled pain patients have shown positive effects on return to work [41]. Thus, reductions in kinesiophobia may reflect reduced pain-related fear of movements related to work tasks.

Baseline values of kinesiophobia among the working cleaners were on average 32-34. These values are comparable to a sample of the Dutch general population [25] and less than the average of 38-40 reported from patients seeking care due to musculoskeletal pain $[40,42,43]$. Although baseline levels were lower in the current study population, significant improvements were still found. This introduces CBTr as a possible valuable prevention strategy to reduce kinesiophobia in workplace interventions as well as in rehabilitation.

No effects on kinesiophobia, strength and balance were seen across the interventions. This finding indicates that contamination was successfully avoided by the cluster randomisation. However, five out of seven measures of strength and balance were numerically impaired in the CBTr-group, and kinesiophobia was numerically increased in the PCT-group. These changes were not significantly different from REF, and conclusions can not be drawn on these aspects. However, for improvements to be fully reflected in the ability to tolerate high physical work demands, interventions to counteract the reduced resources and thus improve both physical and cognitivebehavioural resources would probably be optimal. We therefore suggest that future interventions should integrate both PCT and CBTr in one initiative in the prevention on physical deterioration among workers. Future research is needed to verify this recommendation.

\section{Strengths and limitations}

This study tested new approaches to prevention of health deterioration among 294 female cleaners from nine representative workplaces [14]. The interventions were thoroughly developed and tailored to the specific job group of cleaners. Although adherence rates were rather low, they were not lower than intervention studies in similar job groups [44]. However, the development of the interventions primarily built on a theoretical rationale derived from efficacy studies. Efficacy studies differ from effectiveness studies by being conducted in a context that gives optimal conditions for implementation [45]. Efficacy is necessary to, but not sufficient for effectiveness [45] and implementation is suggested to be thought of as interacting with the efficacy to determine effectiveness [46]. Thus in an effectiveness study, implementation plays an important role in obtaining results. In the current study, two specific efforts were made to support implementation of the interventions. First, workplaces adopting this intervention study were obliged by contract to provide time for the intervention during working hours. Second, each training session was guided by an instructor to personalise the interventions. Although adaption to the workplace setting was performed and pilot studies conducted, the practical rationale behind the interventions could have gained strength, if they had derived from feasibility studies among cleaners. Both inadequate efficacy as well as implementation is a possible reason for the lack of effect in some of the strength parameters. Thus, further efforts to improve implementation and adherence rates of workplace intervention studies in job groups with low socio-economic resources and among workers with low influence on work schedules should be implemented in future study designs.

By the conservative intention-to-treat analyses (with forward and backward carrying of missing observations), a tendency to underestimate the variances appears. It should be mentioned though, that the analyses reported in the results section of this paper follow the standards of the consort statement [26] and are conservatively designed to false positive finding due to avoid bias associated with non-random drop-out. Even with the relatively large drop-out, intention-to-treat analyses were able to reveal significant intervention effects, supporting our hypotheses of the interventions. Nevertheless, given the large standard deviations shown in table 2 it is likely that this study suffers from impaired power and some false negative results may be evident.

A non-significant increase in kinesiophobia was seen in the PCT-group. Since the increase was non-significant, it cannot be ruled out, that it happened by chance. However, according to the fear-avoidance theory of pain, one reaction to an expected painful stimulus may be avoidance behaviour [47]. That is, the individual has certain expectations on the painful consequences of an activity, which lead to avoiding the activity. It is well known, that physical training in itself can introduce an acute pain response [48]. Thus a confirmation of the fearful expectation to physical training may exacerbate the fear of movement and result in the increased kineisophobia seen in the current study. Graded activity has been suggested as treatment method for pain patients 
with high kinesiophobia. With graded activity, loads are introduced gradually and thereby producing disconfirmations of expectations of pain and harm and actual consequences of the activity [47]. In the PCT, exercise intensity was increased gradually and instructors carefully informed the participants that some pain and soreness could be experienced after training. However, no cognitive-behavioural or operant exercises were included. Actually, this was avoided to reduce overlapping interventions. In spite of the insignificance, the numerical increase in kinesiophobia in PCT may encourage that future training interventions corporate such kinesiophobia preventive exercises prior to or concurrent with the training.

\section{Conclusion}

The main finding of this randomised controlled trial was that female cleaners improved their physical and cognitive-behavioural (psychological) resources after three months interventions. The PCT-intervention improved trunk flexion strength and postural balance. The CBTrintervention reduced kinesiophobia, when compared with REF and PCT. This study is the first to reveal such improvements among workers with high physical demands. Indications were found for the increased potential of combining the PCT and CBTr interventions in future workplace interventions among work groups with high physical work demands and high prevalence of pain.

\section{List of abbreviations}

PCT: Physical coordination training; CBTr: Cognitive behavioural theory-based training; REF: Reference group; MVC: Maximal Voluntary Contraction; ITT: Intention to treat

\section{Acknowledgements}

This study was supported by a grant from The Ministry of Culture Committee on Sports Research, Denmark, and conducted as a part of the FINALE program supported by the Danish Working Environment Research Foundation. The study sponsors did not have any involvement in the study design; in the collection, analysis and interpretation data; in the writing of the report; or in the decision to submit the paper for publication.

\section{Author details}

${ }^{1}$ The National Research Centre for the Working Environment, Lers $\varnothing$ Parkallé 105, 2100 Copenhagen, Denmark. ²Department of Exercise and Sports Sciences, University of Copenhagen, Copenhagen, Denmark. ${ }^{3}$ Clinical Alchohol Research Lund University, Lund University, Lund, Sweden. ${ }^{4}$ Institute of Sports Science and Clinical Biomechanics, University of Southern Denmark, Odense, Denmark.

\section{Authors' contributions}

MBJ, KS: Overall design. MBJ, KS, GS: Design of the PCT-intervention. MBJ, KS, JEA: Design of the CBTr-intervention. MBJ, KS, AHO: Conduct of data analyses. MBJ: First drafting of the manuscript. All authors read and approved the final manuscript.

\section{Competing interests}

The authors declare that they have no competing interests.
Received: 16 May 2011 Accepted: 10 October 2011

Published: 10 October 2011

\section{References}

1. Søgaard K, Blangsted AK, Herod A, Finsen L: Work Design and the Labouring Body: Examining the Impacts of Work Organization on Danish Cleaners' Health. Antipode 2006, 581-604.

2. Unge J, Ohlsson K, Nordander C, Hansson GA, Skerfving S, Balogh I: Differences in physical workload, psychosocial factors and musculoskeletal disorders between two groups of female hospital cleaners with two diverse organizational models. Int Arch Occup Environ Health 2007, 81:209-220.

3. Woods V, Buckle P: Musculoskeletal ill health amongst cleaners and recommendations for work organisational change. Int J Ind Erg 2006, 36:61-72.

4. Krause N, Scherzer T, Rugulies R: Physical workload, work intensification, and prevalence of pain in low wage workers: results from a participatory research project with hotel room cleaners in Las Vegas. Am $J$ Ind Med 2005, 48:326-337.

5. Holtermann A, Jorgensen MB, Gram B, Christensen JR, Faber A, Overgaard $K$, et al: Worksite interventions for preventing physical deterioration among employees in job-groups with high physical work demands: Background, design and conceptual model of FINALE. BMC Public Health 2010, 10:120.

6. Flum MR, Siqueira CE, Decaro A, Redway S: Photovoice in the workplace: A participatory method to give voice to workers to identify health and safety hazards and promote workplace change-a study of university custodians. Am J Ind Med 2010, 53:1150-8.

7. Lee PT, Krause N: The impact of a worker health study on working conditions. J Public Health Policy 2002, 23:268-285.

8. Holtermann A, Blangsted AK, Christensen H, Hansen K, Sogaard K: What characterizes cleaners sustaining good musculoskeletal health after years with physically heavy work? Int Arch Occup Environ Health 2009, 82:1015-22.

9. Crombez G, Vlaeyen JW, Heuts PH, Lysens R: Pain-related fear is more disabling than pain itself: evidence on the role of pain-related fear in chronic back pain disability. Pain 1999, 80:329-339.

10. Pedersen MT, Blangsted AK, Andersen LL, Jorgensen MB, Hansen EA, Sjogaard G: The effect of worksite physical activity intervention on physical capacity, health, and productivity: a 1-year randomized controlled trial. J Occup Environ Med 2009, 51:759-770.

11. Andersen LL, Jorgensen MB, Blangsted AK, Pedersen MT, Hansen EA, Sjogaard G: A Randomized Controlled Intervention Trial to Relieve and Prevent Neck/Shoulder Pain. Med Sci Sports Exerc 2008, 40:983-90.

12. Ostelo RW, van Tulder MW, Vlaeyen JW, Linton SJ, Morley SJ, Assendelft WJ: Behavioural treatment for chronic low-back pain. Cochrane Database Syst Rev 2005, CD002014

13. Dahl JC, Nilsson A: Evaluation of a randomized preventive behavioural medicine work site intervention for public health workers at risk for developing chronic pain. Eur J Pain 2001, 5:421-432.

14. Jorgensen MB, Rasmussen CD, Ekner D, Sogaard K: Successful Reach and Adoption of a workplace health promotion RCT targeting a group of high-risk workers. BMC Med Res Methodol 2010, 10:56.

15. Jorgensen MB, Andersen LL, Kirk N, Pedersen MT, Sogaard K, Holtermann A: Muscle Activity during Functional Coordination Training: Implications for Strength Gain and Rehabilitation. J Strength Cond Res 2010, 24:1732-1739.

16. Marhold C, Linton SJ, Melin L: A cognitive-behavioral return-to-work program: effects on pain patients with a history of long-term versus short-term sick leave. Pain 2001, 91:155-163.

17. Linton SJ: Second appendix. To understand patients with pain Lund: Studentlitteratur; 2005, 303-338.

18. Williams M, Teasdale J, Segal Z, Kabat-Zin J: The Mindfull Way Through Depression-Freeing Yourself from Unhappiness Guilford Press; 2007.

19. Essendrop M, Schibye $B$, Hansen K: Reliability of isometric muscle strength tests for the trunk, hands and shoulders. Int J Ind Erg 2001, 28:379-387.

20. Jorgensen MB, Rasmussen CD, Carneiro IG, Flyvholm MA, Olesen K, Ekner D, et al: Health disparities between immigrant and Danish cleaners. Int Arch Occup Environ Health 2011, 84:665-674.

21. Khasnis A, Gokula RM: Romberg's test. J Postgrad Med 2003, 49:169-172. 
22. Prieto TE, Myklebust JB, Hoffmann RG, Lovett EG, Myklebust BM: Measures of postural steadiness: differences between healthy young and elderly adults. IEEE Trans Biomed Eng 1996, 43:956-966.

23. Vlaeyen JW, Kole-Snijders AM, Boeren RG, van EH: Fear of movement/(re) injury in chronic low back pain and its relation to behavioral performance. Pain 1995, 62:363-372.

24. Vlaeyen JW, Morley S: Cognitive-behavioral treatments for chronic pain: what works for whom? Clin J Pain 2005, 21:1-8.

25. Houben RM, Leeuw M, Vlaeyen JW, Goubert L, Picavet HS: Fear of movement/injury in the general population: factor structure and psychometric properties of an adapted version of the Tampa Scale for Kinesiophobia. J Behav Med 2005, 28:415-424.

26. Schulz KF, Altman DG, Moher D: CONSORT 2010 statement: updated guidelines for reporting parallel group randomised trials. BMJ 2010, 340 c332.

27. Antes G: The new CONSORT statement. BMJ 2010, 340:C1432.

28. Rasmussen CD, Jorgensen MB, Carneiro IG, Flyvholm MA, Olesen K, Sogaard $\mathrm{K}$, et al: Participation of Danish and immigrant cleaners in a 1year worksite intervention preventingphysical deterioration. Ergonomics 2011.

29. Olesen K, Carneiro IG, Jorgensen MB, Flyvholm MA, Rugulies R, Rasmussen CD, et al: Psychosocial work environment among immigrant and Danish cleaners. Int Arch Occup Environ Health 2011.

30. Armstrong TJ, Buckle P, Fine $\sqcup$, Hagberg M, Jonsson B, Kilbom A, et al: A conceptual model for work-related neck and upper-limb musculoskeletal disorders. Scand J Work Environ Health 1993, 19:73-84.

31. Holtermann A, Mortensen OS, Burr H, Sogaard K, Gyntelberg F, Suadicani P: Physical demands at work, physical fitness, and 30-year ischaemic heart disease and all-cause mortality in the Copenhagen Male Study. Scand J Work Environ Health 2010, 36:357-365.

32. Faber A, Hansen $\mathrm{K}$, Christensen $\mathrm{H}$ : Muscle strength and aerobic capacity in a representative sample of employees with and without repetitive monotonous work. Int Arch Occup Environ Health 2006, 79:33-41.

33. Vera-Garcia FJ, Elvira JL, Brown SH, McGill SM: Effects of abdominal stabilization maneuvers on the control of spine motion and stability against sudden trunk perturbations. J Electromyogr Kinesiol 2007, 17:556-567.

34. Pedersen MT, Essendrop M, Skotte $J H$, Jorgensen K, Fallentin N: Training can modify back muscle response to sudden trunk loading. Eur Spine J 2004, 13:548-552.

35. Cholewicki J, Silfies SP, Shah RA, Greene HS, Reeves NP, Alvi K, et al: Delayed trunk muscle reflex responses increase the risk of low back injuries. Spine 2005, 30:2614-2620.

36. Tsao H, Galea MP, Hodges PW: Reorganization of the motor cortex is associated with postural control deficits in recurrent low back pain. Brain 2008, 131:2161-2171.

37. Gheldof EL, Crombez G, Van den BE, Vinck J, Van NA, Moens G, et al: Painrelated fear predicts disability, but not pain severity: a path analytic approach of the fear-avoidance model. Eur J Pain 2010, 14:870-879.

38. Feleus A, van DT, Bierma-Zeinstra SM, Bernsen RM, Verhaar JA, Koes BW, et al: Kinesiophobia in patients with non-traumatic arm, neck and shoulder complaints: a prospective cohort study in general practice. BMC Musculoskelet Disord 2007, 8:117.

39. Damsgard E, Dewar A, Roe C, Hamran T: Staying active despite pain: Pain beliefs and experiences with activity-related pain in patients with chronic musculoskeletal pain. Scand J Caring Sci 2010, 25:108-16.

40. Helmhout PH, Staal JB, Heymans MW, Harts CC, Hendriks EJ, de Bie RA: Prognostic factors for perceived recovery or functional improvement in non-specific low back pain: secondary analyses of three randomized clinical trials. Eur Spine J 2010, 19:650-659.

41. Wideman $\mathrm{TH}$, Adams $H$, Sullivan MJ: A prospective sequential analysis of the fear-avoidance model of pain. Pain 2009, 145:45-51.

42. Koumantakis GA, Watson PJ, Oldham JA: Trunk muscle stabilization training plus general exercise versus general exercise only: randomized controlled trial of patients with recurrent low back pain. Phys Ther 2005, 85:209-225.

43. Meijer EM, Sluiter JK, Heyma A, Sadiraj K, Frings-Dresen MH: Costeffectiveness of multidisciplinary treatment in sick-listed patients with upper extremity musculoskeletal disorders: a randomized, controlled trial with one-year follow-up. Int Arch Occup Environ Health 2006, 79:654-664.
44. Pehkonen I, Takala EP, Ketola R, Viikari-Juntura E, Leino-Arjas P, Hopsu L, et al: Evaluation of a participatory ergonomic intervention process in kitchen work. Appl Ergon 2009, 40:115-123.

45. Flay BR: Efficacy and effectiveness trials (and other phases of research) in the development of health promotion programs. Prev Med 1986, 15:451-474.

46. Glasgow RE, Vogt TM, Boles SM: Evaluating the public health impact of health promotion interventions: the RE-AIM framework. Am J Public Health 1999, 89:1322-1327.

47. Vlaeyen JW, de JJ, Geilen M, Heuts PH, van BG: Graded exposure in vivo in the treatment of pain-related fear: a replicated single-case experimental design in four patients with chronic low back pain. Behav Res Ther 2001, 39:151-166.

48. Andersen LL, Kjaer M, Sogaard K, Hansen L, Kryger Al, Sjogaard G: Effect of two contrasting types of physical exercise on chronic neck muscle pain. Arthritis Rheum 2008, 59:84-91.

Pre-publication history

The pre-publication history for this paper can be accessed here: http://www.biomedcentral.com/1471-2458/11/776/prepub

doi:10.1186/1471-2458-11-776

Cite this article as: Jørgensen et al:: A randomised controlled trial among cleaners-Effects on strength, balance and kinesiophobia. BMC Public Health 2011 11:776.

\section{Submit your next manuscript to BioMed Central and take full advantage of:}

- Convenient online submission

- Thorough peer review

- No space constraints or color figure charges

- Immediate publication on acceptance

- Inclusion in PubMed, CAS, Scopus and Google Scholar

- Research which is freely available for redistribution

Submit your manuscript at www.biomedcentral.com/submit
C Biomed Central 